\title{
A influência da vaidade no comportamento de compra do consumidor masculino das gerações $X$ e $Y$
}

\author{
Bianca Mazurkewiez \\ Universidade Regional do Noroeste do Estado do Rio Grande do Sul - Unijui \\ mazurkewiez-bianca@bol.com.br \\ Adriane Fabricio \\ Universidade Regional do Noroeste do Estado do Rio Grande do Sul - Unijui \\ adrianefabricio@yahoo.com.br \\ Vanessa Hasper Dessbesell \\ Universidade Regional do Noroeste do Estado do Rio Grande do Sul - Unijui \\ vanessahasper@hotmail.com \\ Nairana Radtke Bussler \\ Universidade Regional do Noroeste do Estado do Rio Grande do Sul - Unijui \\ nacaneppele@hotmail.com \\ Universidade Regional do Noroeste do Estado do Rio Grande do Sul - Unijui \\ rotili@terra.com.br \\ Luis Felipe Lopes \\ Universidade Federal de Santa Maria - UFSM \\ Iflopes67@yahoo.com.br
}

Resumo: O objetivo deste artigo é identificar como a vaidade influencia no comportamento de compra do consumidor masculino das gerações $\mathrm{X}$ e $\mathrm{Y}$. Trata-se de uma pesquisa descritiva, utilizando-se do método de levantamento (survey). A amostra foi de 91 homens de um município da região noroeste do estado do Rio Grande do Sul. Como principais resultados, evidencia-se que há tendência dos consumidores masculinos da geração $Y$ comprar e consumir em maior escala que a geração $X$. Assim, na compra de produtos de beleza, $60,0 \%$ dos homens da geração $X$ e $74,7 \%$ da geração $\mathrm{Y}$ compram produtos de beleza ao menos uma vez ao mês. No que tange a frequência de compra, observou-se que os homens da geração $X$ efetuam compras em intervalos de tempo mais prolongados em relação aos homens da geração $Y$ e, neste mesmo sentido, os homens da geração $Y$ consomem mais produtos de beleza e cuidados com a estética, tais como depilação, manicure, cirurgias plásticas, do que os homens da geração X.

Palavras-Chave: Consumidor Masculino; Gerações X e Y; Vaidade.

\section{The influence of vanity in the shopping behavior of the male consumer of generations $X$ and $Y$}

Abstract: The objective of this article is to identify how vanity influences the buying behavior of the male consumers of the generations $\mathrm{X}$ and $\mathrm{Y}$. This is a descriptive research, using the survey method. The sample is 91 men from a municipality in the northwest region of the state of Rio Grande do Sul. As the main results, it is evident that there is a tendency of the male consumers of generation $Y$, to buy and to consume on a larger scale than the generation $\mathrm{X}$. So in the purchase of beauty products, $60.0 \%$ of men of generation $X$ and $74.7 \%$ of generation $Y$, buy beauty products at least once a month. Regarding the frequency of purchase it was observed that the men of generation $X$ make purchases in 
longer intervals of time than the men of the generation $Y$ and in this same sense the men of generation $Y$ consume more products of beauty and care with the aesthetics such as waxing, manicuring, plastic surgeries than men of generation $\mathrm{X}$.

Keywords: Male Consumer; Generations X and Y; Vanity.

\section{INTRODUÇÃO}

Atualmente as pessoas estão cada vez mais preocupadas com a aparência física, procurando sempre estar bem vestidas em busca do corpo perfeito, seja para chamar atenção, por um status social ou mesmo para promover o seu marketing pessoal. Todo esse cuidado demonstra que questões relacionadas à vaidade das pessoas estão alcançando um maior espaço, principalmente no sexo masculino, visto que algumas atitudes de cuidados com o corpo não eram identificadas, e hoje estão em pauta.

Webster (2001) acredita que a vaidade difere do orgulho em uma conotação mais ampla de preocupação com a imagem, com comportamento direcionado para melhorar a impressão percebida pelos outros e da avaliação pessoal. O orgulho é considerado pela sociedade como imoral, ao contrário da vaidade, que é associada com aspectos positivos de comportamento.

A preocupação das pessoas com relação a sua aparência está cada vez maior, o segmento de beleza vem oferecendo no mercado em geral uma ampla gama de bens e serviços aos consumidores desse segmento. $O$ objetivo passou a ser o bem-estar, a saúde e a higiene, bem como a busca constante pela beleza. Para Blackwell, Miniard e Engel (2005), os estágios de consumo envolvem anúncios, que chamam a atenção do consumidor, para que ele possa adquirir e corresponder a um estímulo de necessidade.

As mudanças e inovações vêm transformando o comportamento dos consumidores. Já se foi o tempo em que só as mulheres cuidavam da beleza enquanto aos homens não cabia tais prerrogativas. Hoje há um aumento considerável do público masculino preocupado com sua vaidade, aparência física e bem-estar.

O "novo homem", de acordo com Bastos (2005, p. 15), se preocupa com vaidade e beleza, chega a ser até mais vaidoso que as mulheres e consome produtos de beleza e cuidados com a estética, tais como depilação de sobrancelha e 
manicure. Atitudes como frequentar clínicas de massagens, clínicas de cirurgia plástica, estéticas e salões de beleza fazem parte, cada vez mais, do seu cotidiano.

O crescimento do público masculino preocupado com a aparência física e com cuidados estéticos está impulsionando o segmento a investir mais em suas necessidades. Se faz necessário conhecer como se comporta o consumidor das gerações $\mathrm{X}$ e $\mathrm{Y}$ e quais são as influencias que a vaidade exerce na hora da compra desses indivíduos, pois esse com certeza será um diferencial que a empresa apresentará frente ao mercado competitivo.

Diante deste contexto, o objetivo deste artigo é identificar como a vaidade influencia o comportamento de compra de consumidores masculinos das gerações $X$ e $\mathrm{Y}$ de uma cidade localizada na região noroeste do estado do Rio Grande do Sul.

\section{REFERENCIAL TEÓRICO}

\subsection{Comportamento de compra do consumidor masculino}

A análise do comportamento do consumidor está em ascensão tanto para pesquisadores como para as empresas, que precisam entender o seu mercado-alvo e adequar suas ações para as preferências e exigências dos consumidores. Para Wilkie (1994 apud Naves 2012), o comportamento do consumidor pode ser definido como as atividades mentais, físicas e emocionais que as pessoas fazem quando selecionam, compram, usam e descartam produtos e serviços como uma forma de satisfazer desejos e necessidades.

O autor Kotler (1998) explica que a área do comportamento do consumidor estuda como as pessoas, os grupos e as organizações selecionam, compram, usam e descartam os produtos, serviços, ideias ou experiências para satisfazer suas necessidades e seus desejos. Já Blackwell, Miniard e Engel (2005) a definem como as atividades diretamente envolvidas em obter, consumir e dispor de produtos e serviços, incluindo os processos decisórios que antecedem e sucedem essas ações.

De acordo com Schiffman e Kanuk (2000), é importante para as empresas e futuros administradores, profissionais de marketing entender por que e como indivíduos tomam suas decisões de consumo, para que possam realizar seus planejamentos estratégicos de marketing coerentemente. Sheth, Mittal e Newman 
(2001), ao abordarem o tema sob um prisma mais mercadológico, destacam os processos físicos e mentais realizados pelo consumidor, que resultam nas decisões e ações de compra. A atividade física está relacionada, por exemplo, à visita a uma loja e à conversa com o vendedor; enquanto a mental refere-se, entre outros aspectos, à análise da qualidade e às experiências com o produto.

Rocha e Christensen (1999) afirmam que alterações no comportamento dos consumidores são, muitas vezes, o resultado de adaptações a mudanças ambientais. Algumas dessas alterações poderão ser de caráter conjuntural, desaparecendo com a volta da situação anterior. Outras, contudo, são de caráter estrutural, em nível mais profundo tais como, as atitudes, crenças e comportamentos.

Ao longo do tempo, estudos sobre o comportamento de compra de consumidores feminino e masculino vêm despontando quando o assunto é comparálos, sendo que o resultado desses estudos se tornou fundamental para as organizações, pois elas usam essas informações como oportunidades de negócios e vantagens competitivas em relação aos concorrentes. Sheth, Mittal e Newman (2001) afirmam que os homens estão sendo forçados assumir o papel de comprador, e muitos ainda são novatos nessa tarefa, aprendendo as habilidades necessárias.

Em termos psicológicos, o sexo masculino foi considerado em resultados de investigações como sendo mais "assertivo e ativo" e o feminino "mais sensível à interdependência social" (KOLYESNIKOVA, DODD, WILCOX, 2009). O público masculino cada vez mais vem demonstrando sua força, impulsionando o mercado da vaidade, e as empresas atentas a esse novo comportamento estão em busca de satisfazer seus consumidores.

\subsection{Vaidade}

Segundo Netemeyer, Burton, Lichtenstein (1995), a vaidade está relacionada ao materialismo, justificando a importância de estudos sobre este construto e seu impacto no comportamento do consumidor. Thompson e Hirschman (1995) ressaltam ainda que a dedicação a fim de alcançar o corpo desejado estimula o consumo de vários serviços e produtos de uma indústria multibilionária com foco explícito no corpo dos consumidores: programas de dietas, equipamentos de 
ginástica, cosméticos, cirurgias plásticas, alimentos ligth e diet, livros e revistas com imagens de corpos idealizados.

As experiências e percepções dos consumidores em relação a sua aparência física têm grande influência no comportamento de consumo e nos significados atribuídos aos produtos e serviços relativos a questões estéticas. No entanto, o corpo ideal construído pelas imagens da mídia está longe do corpo que a média da população possui, e desvios dos padrões idealizados culturalmente são encarados como um problema pelas pessoas, gerando consequências pessoais significantes (THOMPSON, HIRSCHMAN, 1995).

Em todo o mundo, cosméticos e produtos de higiene pessoal constituem uma indústria de 45 bilhões de dólares. Nos Estados Unidos, milhões de dólares são gastos todo ano em propagandas para convencer os consumidores de que os produtos e serviços estéticos oferecidos irão torná-los atrativos e, assim, melhorar seu bem-estar (BLOCH, RICHINS, 1992).

A vaidade pode afetar o consumo de cosméticos e tratamentos, a frequência de cuidados estéticos e o envolvimento do indivíduo com a beleza. A busca pela beleza leva consumidores a consumir bens como adornos e também os leva a modificar o próprio corpo (BLOCH; RICHINS, 1993).

Segundo Neves (2012), vaidade nunca foi uma prerrogativa feminina, porém a vontade masculina de expressar a preocupação com a beleza era um impulso delimitado por preconceitos que, felizmente, foram derrubados a partir do final dos anos 90, com o surgimento da onda metrossexual. O homem moderno está cada vez mais preocupado em fazer parte da nova sociedade, onde a busca pela perfeição está cada dia mais intensa. As exigências deixam de atingir apenas as mulheres e começam a preocupar o mundo masculino (BARCELLINI, 2014).

Para Neves (2012), a partir do momento em que o "desleixo como sinal de masculinidade" tornou-se um conceito totalmente na contramão, a indústria cosmética passou a investir em produtos multifuncionais, com ativos que oferecem melhor desempenho para a pele e para os cabelos dos homens, e em embalagens mais práticas e sóbrias, tanto que uma pesquisa realizada pela Associação Brasileira de Embalagem (Abre), de São Paulo, em novembro de 2009, mostrou que os homens priorizam a praticidade, as informações e a possibilidade de reutilização das embalagens. Constatou também que existem diferenças entre os homens casados e os solteiros. Os primeiros preferem embalagens maiores e econômicas, 
enquanto os segundos valorizam as informações e os itens que proporcionem comodidade, praticidade e conforto.

Portanto, vaidade não é mais coisa de mulher: os homens estão a cada vez mais exigentes com seu bem-estar e aparência, e esse público tem impulsionado o mercado da vaidade no Brasil e no mundo. No mundo moderno, vaidade é coisa de homem sim.

\subsection{Geração X}

Kullock (2010) propõe que uma geração engloba conjunto de indivíduos nascidos em uma mesma época, influenciados por um contexto histórico especifico que determina comportamentos, causando impacto direto na evolução da sociedade. Coelho (2011) define a Geração X, nascidos entre 1960 a 1980, como profissionais que construíram suas carreiras em longos anos, na maior parte das vezes cresceram juntamente com as organizações em que atuam, sabem se comunicar, têm visão estratégica, zelam por seus empregos, pela segurança do mesmo.

Para Stauffer (2003), para motivar esta geração diga-lhes o que precisa ser feito, mas não como fazê-lo. Dê-lhes muitas tarefas, porém deixe que eles estabeleçam as prioridades, evite usar clichês ou expressões da moda, forneça feedback sincero e com frequência. As pessoas não identificam o êxito da mesma forma que seus pais identificavam. Ao contrário nutrem certo cinismo e desilusão em relação aos seus valores, são mais céticos (LOMBARDÍA, STEIN, RAMÓN, 2008). Oliveira (2009) pontua que essa geração foi totalmente influenciada por programas de televisão, tanto no que diz respeito à educação, quanto à rotina familiar. Tal influência também envolveu um aumento exacerbado dos apelos consumistas, reordenando e orientando o modo de viver e agir das pessoas.

Também podem ser consideradas pessoas egoístas. A geração é marcada pelo pragmatismo e autoconfiança nas escolhas, e busca promover a igualdade de direitos e de justiça em suas decisões (OLIVEIRA, 2009). Complementando, Lombardía, Stein e Ramón (2008) explicitam que as pessoas pertinentes a essa geração são conservadoras, materialistas e possuem aversão à supervisão. As pessoas da geração $X$ desconfiam de verdades absolutas, são positivistas, autoconfiantes, cumprem objetivos e não os prazos, além de serem muito criativos. 


\subsection{Geração Y}

A Geração Y é definida por Maldonado (2005) como a primeira geração da história a ter maior conhecimento do que as anteriores de uma área essencial: a tecnologia. Querem trabalhar para viver, mas não viver para trabalhar. Captando os acontecimentos em tempo real e se conectando com uma variedade de pessoas, desenvolveram a visão sistêmica e aceitam as diversidades.

Segundo Lipkin e Perrymore (2010), os nascidos entre os anos de 1980 e o ano de 2000 pertencem à Geração $\mathrm{Y}$ e são caracterizados por ser uma geração talentosa, estimulada, consciente, exigente e criativa. De acordo com Stauffer (2003), para motivar esta geração é preciso dar-Ihes oportunidade de aprendizado constante e aperfeiçoamento de suas habilidades, conhecendo os objetivos de cada integrante da equipe e mostrando como as tarefas que Ihes foi dada são adequadas para atingir esses objetivos.

O autor Serrano (2010) a define como a geração que está sempre conectada, que procura informação fácil e imediata, prefere computadores a livros, e-mails a cartas e digitar ao invés de escrever. Veloso, Dutra e Nakata (2008) consideram que esta geração possui outro conceito de trabalho, baseado em um contrato psicológico diferente do que foi estabelecido pelos seus antecessores. Identifica o trabalho como uma fonte de satisfação e aprendizado, muito mais do que uma fonte de renda. Isso favorece que os conceitos de carreira, promoção, estabilidade e vínculo profissional, aspectos relativos à vida organizacional bastantes valorizados pelas gerações anteriores, passem a ser analisados sobre novas perspectivas.

Para Oliveira (2009), as pessoas dessa geração valorizam menos a permanência em uma única empresa e mantém mais lealdade a si mesma, porém são mais fáceis de serem recrutadas, uma vez que buscam trabalhar com liberdade, flexibilidades e criatividade, sentindo, ainda, necessidades de avaliações contínuas.

Engelmann (2007) enfatiza que não respeitam cargos ou currículos, mas demonstram admiração por competência real e comportamento ético. Conseguem acesso fácil às informações e são sensíveis às injustiças. Contudo, são impacientes, folgados, distraídos, superficiais e insubordinados, só fazendo o que gostam e quando percebem que há algum sentido ou alguma recompensa. Possuem dificuldades de acatar os limites e adoram refeições rápidas. 


\section{METODOLOGIA}

Com o intuito de alcançar o objetivo do estudo, pode-se afirmar que esta pesquisa é de natureza aplicada, de abordagem qualitativa e quantitativa; quanto aos seus objetivos é descritiva, e como procedimentos técnicos, levantamento (survey).

Segundo Andrade (2010), é impossível estudar uma população inteira, por isso os elementos estudados fazem parte de uma amostra da população ou do universo, escolhendo-se determinada quantidade dos sujeitos. Na pesquisa, o universo amostral foram homens das gerações $X$ e $Y$ com idade entre 20 e 45 anos, nascidos entre 1970 a 1995, que residem em uma cidade do Interior do Estado do Rio Grande do Sul, sendo que a escolha dos participantes foi aleatória e por conveniência. Foram distribuídos 186 questionários, dos quais 95 retornaram, 4 foram anulados por estarem incompletos ou não pertencerem às gerações foco do estudo, sendo considerados como validados e utilizados 91 questionários.

Quanto ao instrumento de pesquisa, foi utilizado um questionário, contendo vinte e seis (26) questões relacionadas ao tema; este foi recriado a partir da versão elaborada pelas autoras Marchiori (2014) e Stamm (2014), sendo 7 perguntas abertas caracterizadas como não estruturadas, buscando auditar a quantidade de produtos de beleza que cada homem possui hoje, verificar a frequência que utiliza produtos de beleza, e o valor que destina mensalmente para estes, analisar os locais que realizam as compras, as marcas de seu maior e menor agrado e o significado da vaidade. Também com questões de múltipla escolha, caracterizado como estruturado, sendo essas dezenove (19) buscando conhecer o perfil, a frequência de compras, a razão pela qual utilizam produtos de beleza e os fatores que influenciam o consumo dos produtos de beleza.

A estrutura do questionário foi também composta por escalas nominais. Conforme explica Malhotra (2001 apud Marchiori 2014), nas escalas nominais os números são utilizados como rótulos ou etiquetas, apenas para a identificação e classificação dos objetos e com alternativas fechadas. 


\section{ANÁLISE DOS RESULTADOS}

Inicia-se a apresentação dos resultados pela identificação do perfil da amostra, seguida da análise da influência da vaidade no comportamento de compra do consumidor masculino da amostra em questão - 91 respondentes.

\subsection{Caracterização do perfil dos respondentes da pesquisa}

Salomon (2002) destaca que a idade influencia no comportamento de compra, e os consumidores de vários grupos possuem necessidades e desejos muito diferentes uns dos outros. Entre os respondentes da Geração X, a maioria tem 40 anos (24\%), 41 anos (14\%), bem como os de 42 anos e 39 (14\%). Já a maioria dos respondentes da geração $Y$ tem 21 anos (16\%), em seguida os de 25 anos (10\%), os de 22 anos (9\%) e de 24 anos (9\%).

$\mathrm{O}$ perfil da maioria da geração $\mathrm{X}$ corresponde a homens casados ou em união (85,8\%), maioria com renda mensal de 3 a 6 salários mínimos $(47,6 \%)$ e maioria cursando ou formado no ensino superior $(52,4 \%)$. Já o perfil da maioria da geração $Y$ corresponde a homens em sua maioria solteiros $(64,3 \%)$, com renda mensal de 1 a 3 salários mínimos (65,8\%), cursando o ensino superior $(67,1 \%)$ (Tabela 1).

Tabela 1 - Perfil dos respondentes da pesquisa.

\begin{tabular}{|c|c|c|c|}
\hline Variáveis & Alternativas & Geração X & Geração Y \\
\hline & & $\%$ & $\%$ \\
\hline \multirow[t]{4}{*}{ Estado civil } & Solteiro & 9,5 & 64,3 \\
\hline & Casado/União Estável & 85,8 & 30,0 \\
\hline & Divorciado & 4,8 & 2,9 \\
\hline & Viúvo & - & 2,9 \\
\hline & Até 1 salário mínimo & 4,8 & 5,7 \\
\hline \multirow[t]{4}{*}{ Renda Mensal } & De 1 até 2 salários & 4,8 & 32,9 \\
\hline & De 2 até 3 salários & 28,6 & 32,9 \\
\hline & De 3 até 6 salários & 47,6 & 20,0 \\
\hline & Acima de 6 salários & 14,3 & 8,6 \\
\hline \multirow{5}{*}{ Escolaridade } & Ens. Superior Comp. & 23,8 & 7,1 \\
\hline & Ens. Superior Curs. & 28.6 & 67,1 \\
\hline & Ens. Médio & 19,1 & 22,9 \\
\hline & Ens. Fundamental & 19,0 & 2,9 \\
\hline & Outro & 9,5 & - \\
\hline
\end{tabular}


O fato da maioria dos homens da geração $Y$ permanecerem solteiros $(64,3 \%)$ pode ser simplesmente pela idade dos mesmos ou também, como Engelmann (2007) lembra, por ser uma geração formada por pessoas superficiais e insubordinadas que só fazem o que gostam.

Com os dados apresentados tem-se a percepção de que os homens da geração $\mathrm{Y}$, devido a estarem em um ciclo de vida diferenciado da geração $\mathrm{X}$, ainda estão em processo de formação acadêmica (67,10\%), pois apenas $7,10 \%$ da geração $Y$ possuem formação superior que permite acesso a maiores salários no mercado de trabalho. Veloso, Dutra, Nakata (2008) consideram que a geração $Y$ possui outro conceito de trabalho, baseado em um contrato psicológico diferente do que foi estabelecido pelos seus antecessores. Identifica o trabalho como uma fonte de satisfação e aprendizado, muito mais do que uma fonte de renda.

\subsection{Influência da vaidade no comportamento de compra do consumidor masculino}

Para os homens, há algumas décadas, admitir sua vaidade era uma tarefa difícil, pois isso era considerado um traço feminino, um homem vaidoso era visto com preconceito. Hoje, o preconceito com a vaidade masculina está diminuindo, a maior parte da sociedade já consegue entender que cuidar melhor da própria aparência não precisa ser exclusividade do mundo feminino. Os homens também têm necessidades e precisam de cuidados especiais, melhorando a autoestima e seu bem-estar.

Com relação à frequência com que os homens usam os produtos de beleza, tanto a maioria da geração $X(62 \%)$ quanto da geração $Y(70 \%)$ utilizam, mas quanto a frequência da compra dos mesmos verificou-se que os homens da geração $X$ efetuam compras em intervalos de tempo mais prolongados que os homens da geração $Y$, ou seja, $90 \%$ dos homens da geração $X$ compram até uma vez por mês, enquanto que $71,5 \%$ dos homens da geração $Y$ compram de uma a três vezes ao mês (Tabela 2). 
Tabela 2 - Frequência de compra e uso de produtos de beleza.

\begin{tabular}{|c|c|c|c|}
\hline Variáveis & Alternativas & Geração X & Geração Y \\
\hline & & $\%$ & $\%$ \\
\hline \multirow[t]{4}{*}{$\begin{array}{l}\text { Frequência } \\
\text { compra }\end{array}$} & $\begin{array}{l}\text { Menos de } 1 \text { vez por } \\
\text { mês }\end{array}$ & 40,0 & 25,7 \\
\hline & Uma vez por mês & 50,0 & 42,9 \\
\hline & Duas a três por mês & 10,0 & 28,6 \\
\hline & $\begin{array}{l}\text { Quatro ou mais vezes } \\
\text { por semana }\end{array}$ & - & 2,9 \\
\hline \multirow{6}{*}{$\begin{array}{l}\text { Frequência de } \\
\text { uso }\end{array}$} & 1 a 3 vezes ao dia & - & 6,0 \\
\hline & Diariamente & 62,0 & 70,0 \\
\hline & $\begin{array}{llll}1 & \text { a } & 4 & \text { vezes }\end{array}$ & 10,0 & 13,0 \\
\hline & semana & - & 3,0 \\
\hline & Muita & 14,0 & 7,0 \\
\hline & $\begin{array}{l}\text { Pouca } \\
\text { Em branco }\end{array}$ & 14,0 & 1,0 \\
\hline
\end{tabular}

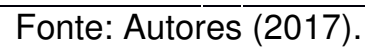

Segundo Neves (2012), vaidade nunca foi uma prerrogativa feminina, porém a vontade masculina de expressar a preocupação com a beleza era um impulso delimitado por preconceitos que, felizmente, foram derrubados a partir do final dos anos 90, com o surgimento da onda metrossexual.

Quanto às cirurgias plásticas, apenas 3\% da geração $Y$ responderam que já fizeram (nariz e orelha), enquanto na geração $X 100 \%$ respondeu que não fez nenhum tipo de intervenção. Quanto a desejarem f//azer cirurgias plásticas, $100 \%$ da geração $X$ diz não querer, enquanto $11 \%$ da geração $Y$ responderam $\operatorname{sim} e, 3 \%$ deixaram em branco. Quando perguntados quais cirurgias plásticas gostariam de realizar, a geração X 100\% não gostariam de realizar cirurgias plásticas, e, na geração $\mathrm{Y}, 70 \%$ gostariam de realizar cirurgias no nariz, seguindo $20 \%$ na barriga e por fim $10 \%$ na orelha (Tabela 3 ).

Tabela 3 - Cirurgias plásticas.

\begin{tabular}{|c|c|c|c|}
\hline Variáveis & Alternativas & Geração X & Geração Y \\
\hline & & $\%$ & $\%$ \\
\hline \multirow{2}{*}{$\begin{array}{l}\text { Já fizeram } \\
\text { cirurgia } \\
\text { plástica }\end{array}$} & Sim & - & 3,0 \\
\hline & Não & 100 & 97,0 \\
\hline \multirow{5}{*}{$\begin{array}{l}\text { Gostaria de } \\
\text { fazer plástica }\end{array}$} & Em branco & - & 3,0 \\
\hline & Sim & 100 & 11,0 \\
\hline & Não & - & 86,0 \\
\hline & Barriga & $\mathrm{N} / \mathrm{R}$ & 20,0 \\
\hline & Orelha & $\mathrm{N} / \mathrm{R}$ & 10,0 \\
\hline
\end{tabular}

Fonte: Autores (2017). 
Thompson e Hirschman (1995) ressaltam ainda que a dedicação a fim de alcançar o corpo desejado estimula o consumo de vários serviços e produtos de uma indústria multibilionária com foco explícito no corpo dos consumidores: programas de dietas, equipamentos de ginástica, cosméticos, cirurgias plásticas, alimentos ligth e diet, livros e revistas com imagens de corpos idealizados. Com base nos resultados da Tabela 3, verificou-se que cirurgia plástica representa uma importante divergência de opinião entre as gerações. Enquanto todos respondentes da geração $X$ não esboçam desejos de realizar cirurgias plásticas, $11 \%$ dos homens pesquisados na geração $\mathrm{Y}$ manifestaram interesse nessa alternativa cirúrgica para alcançar o corpo desejado.

O "novo homem", de acordo com Bastos (2005, p. 15), se preocupa com vaidade e beleza, chega a ser até mais vaidoso que as mulheres e consome produtos de beleza e cuidados com a estética tais como depilação de sobrancelha e manicure. Atitudes como frequentar clínicas de massagens, clínicas de cirurgia plástica, estéticas e salões de beleza fazem parte, cada vez mais, do seu cotidiano; com os dados da Tabela 4 pode-se corroborar com esse dado, à medida que $57 \%$ dos homens da geração $X$ frequentam salão de beleza e $79 \%$ da geração $Y$.

Enquanto $63 \%$ dos homens da geração $X$ e $52 \%$ da geração $Y$ pesquisados afirmam que o motivo prioritário para a visita ao salão de beleza é o corte de cabelo, os demais pesquisados da geração $X$ afirmam que vão ao salão de beleza em busca de cuidados como depilação $7 \%$, barba $7 \%$, limpeza de pele $3 \%$ e massagem $7 \%$. Já na geração $Y$ os cuidados são: depilação $8 \%$, barba $21 \%$, sobrancelha $11 \%$, manicure e pedicure $2 \%$, limpeza de pele $2 \%$ e massagem $4 \%$.

Os pesquisados também foram perguntados se praticam depilação, 19\% correspondente à geração $X$ responderam sim, fazem depilação, assim como da geração $Y(36 \%)$. Ainda com relação à depilação, foram perguntadas as gerações em quais partes do corpo já realizaram, $17 \%$ da geração $X$ disseram que fazem depilação no abdômen, peito e pernas, 33\% declararam que realizam depilação no corpo todo. Já os respondentes da geração $\mathrm{Y}, 12 \%$ responderam que já fizeram depilação no abdômen, $6 \%$ no rosto, $42 \%$ no peito, $6 \%$ pernas e costas assim como axila e, por fim, $15 \%$ responderam que fazem depilação no corpo todo. 
Tabela 4 - Cuidados com o corpo.

\begin{tabular}{|c|c|c|c|}
\hline Variáveis & Alternativas & $\begin{array}{l}\text { Geração } \\
\text { X }\end{array}$ & Geração Y \\
\hline & & $\%$ & $\%$ \\
\hline \multirow[t]{2}{*}{ Frequenta salão de beleza } & Sim & 57,0 & 79,0 \\
\hline & Não & 43,0 & 21,0 \\
\hline \multirow{7}{*}{$\begin{array}{l}\text { Frequência que vão ao } \\
\text { salão }\end{array}$} & Em branco & 33,0 & 20,0 \\
\hline & Duas vezes ao mês & 5,0 & 4,0 \\
\hline & Mensalmente & 48,0 & 70,0 \\
\hline & A cada 2 meses & 5,0 & 3,0 \\
\hline & A cada 3 meses & - & 1,0 \\
\hline & Em ocasiões especiais & - & 1,0 \\
\hline & Muito pouco & 10,0 & - \\
\hline \multirow{9}{*}{$\begin{array}{l}\text { Que cuidados você busca } \\
\text { no salão de beleza }\end{array}$} & Corte & 63,0 & 52,0 \\
\hline & Depilação & 7,0 & 8,0 \\
\hline & Barba & 7,0 & 21,0 \\
\hline & Sobrancelha & 7,0 & 11,0 \\
\hline & Manicure e pedicure & - & - \\
\hline & Limpeza de pele & 3,0 & 3,0 \\
\hline & Pintura, mechas, etc. & - & - \\
\hline & Massagem & 7,0 & 4,0 \\
\hline & Em branco & 7,0 & 1,0 \\
\hline \multirow{3}{*}{ Praticam depilação } & Sim & 19,0 & 36,0 \\
\hline & Não & 81,0 & 63,0 \\
\hline & Em branco & - & 1,0 \\
\hline & Abdômen & 17,0 & 22,0 \\
\hline Partes do corpo já & Rosto & - & 6,0 \\
\hline \multirow{6}{*}{ realizou depilação } & Peito & 17,0 & 42,0 \\
\hline & Pernas & 17,0 & 6,0 \\
\hline & Costas & - & 6,0 \\
\hline & Axilas & - & 6,0 \\
\hline & Corpo todo & 33,0 & 15,0 \\
\hline & Em branco & 17,0 & 6,0 \\
\hline
\end{tabular}

Fonte: Autores (2017).

Com base na questão "por que você não cuida mais do visual?", 48\% da amostra de respondentes da geração $X$ alegam falta de tempo, enquanto $37 \%$ da geração $Y$, seguido de falta de dinheiro, onde 14 correspondendo à geração $X, 23 \%$ a geração $Y$, "não sei como me cuidar melhor" $24 \%$ dos homens da geração $X, 14 \%$ da geração $\mathrm{Y}$, por fim, "tenho preguiça" 10\% correspondente à geração $\mathrm{X}$, sendo 23\% geração $X$ (Tabela 5$)$. 
Tabela 5 - Cuidados com o visual.

\begin{tabular}{|c|c|c|c|}
\hline Variáveis & Alternativas & Geração X & Geração Y \\
\hline & & $\%$ & $\%$ \\
\hline \multirow{5}{*}{$\begin{array}{l}\text { Porque você } \\
\text { não cuida mais } \\
\text { do visual }\end{array}$} & Falta de tempo & 48,0 & 37,0 \\
\hline & Falta de dinheiro & 14,0 & 23,0 \\
\hline & $\begin{array}{l}\text { Não sei como me } \\
\text { cuidar melhor }\end{array}$ & 24,0 & 14,0 \\
\hline & Tenho preguiça & 10,0 & 23,0 \\
\hline & Em branco & 5,00 & 3,00 \\
\hline \multirow{3}{*}{ Você faz dieta } & Sim & 29,0 & 27,0 \\
\hline & Não & 67,0 & 70,0 \\
\hline & Em branco & 5,00 & 3,00 \\
\hline \multirow{3}{*}{$\begin{array}{l}\text { Está feliz com } \\
\text { seu peso }\end{array}$} & Abaixo & 14,3 & 5,70 \\
\hline & Acima & 42,9 & 32,9 \\
\hline & Feliz & 42,9 & 61,4 \\
\hline
\end{tabular}

Também foram questionados se já fizeram dieta: $29 \%$ da geração X e $27 \%$ da Y responderam que sim. Com relação ao peso, foi perguntado se estão felizes, $14,3 \%$ da geração $X$ se dizem abaixo do peso, já da geração $Y 5,7 \%$, seguindo acima do peso da geração $X$ correspondem a 42,9\% e da geração $Y$ 32,9\%; por fim, os que responderam que estão felizes com seus pesos: $42,9 \%$ da geração $X$, enquanto $61,4 \%$ da geração $Y$.

A partir da frequência das respostas, são apresentados os produtos beleza que os homens de cada geração utilizam todos os dias (Tabela 6). Na geração $X$ : 23\% shampoo, 24\% perfume, 21\% desodorante, 12\% gel. Enquanto da geração Y: $20 \%$ shampoo, $11 \%$ condicionador, $19 \%$ perfume, $18 \%$ desodorante, $12 \%$ gel.

Foram perguntados quais os atributos que buscam nos produtos de beleza e cosméticos quando estão decidindo uma compra. $85,7 \%$ dos homens da geração $X$ responderam que o principal atributo que desejam em um produto de beleza é a qualidade, em segundo lugar o preço (81\%), em terceiro a marca (76,2\%), quarto a indicação de um profissional $(52,4 \%)$, em quinto lugar está a indicação de amigos $47,6 \%$, a distribuição dos produtos corresponde a $38,1 \%$ e, por fim, atendimento ao cliente e atendimento do vendedor, com $28,6 \%$.

A geração $Y$ também foi questionada sobre quais atributos busca nos produtos: $72,9 \%$ responderam que o principal atributo é a qualidade, em segundo lugar o preço $(54,3 \%)$, em terceiro a marca $(58,6 \%)$, seguindo a indicação de um profissional (37,1\%), em quinto lugar está a indicação de amigos (22,9\%), a distribuição dos produtos $(15,7 \%)$, atendimento ao cliente $(34,3 \%)$ e atendimento do vendedor corresponde a $34,3 \%$. 
Tabela 6 - Produtos de beleza.

\begin{tabular}{|c|c|c|c|}
\hline Variáveis & Alternativas & Geração X & Geração Y \\
\hline & & $\%$ & $\%$ \\
\hline \multirow{12}{*}{$\begin{array}{l}\text { Quais produtos } \\
\text { você utiliza } \\
\text { todos os dias }\end{array}$} & Creme hidratante & 5,0 & 4,0 \\
\hline & Shampoo & 23,0 & 20,0 \\
\hline & Condicionador & 6,0 & 11,0 \\
\hline & Acessórios & 4,0 & 4,0 \\
\hline & Perfume & 24,0 & 19,0 \\
\hline & Água de colônia & - & 1,0 \\
\hline & Desodorante & 21,0 & 18,0 \\
\hline & Espuma de barbear & 3,0 & 6,0 \\
\hline & Loção & 1,0 & 2,0 \\
\hline & Creme depilatório & - & 1,0 \\
\hline & Gel & 12,0 & 12,0 \\
\hline & Protetor solar & 1,0 & 2,0 \\
\hline \multirow{8}{*}{$\begin{array}{l}\text { Ordem de } \\
\text { importância } \\
\text { dos atributos } \\
\text { de compras }\end{array}$} & Qualidade & 85,7 & 72,9 \\
\hline & Preço & 81,0 & 54,3 \\
\hline & Indicação de profis. & 52,4 & 37,1 \\
\hline & Marca & 76,2 & 58,6 \\
\hline & Indicação de amigos & 47,6 & 22,9 \\
\hline & Atendimento cliente & 28,6 & 34,3 \\
\hline & Distribuição & 38,1 & 15,7 \\
\hline & Atend. Vendedor & 28,6 & 34,3 \\
\hline
\end{tabular}

Fonte: Autores (2017).

A respeito dos dados obtidos com a questão os cuidados que os homens têm com a barba, $67 \%$ da geração $X$ diz estar sempre com a mesma bem-feita, enquanto $30 \%$ da geração $Y, 29 \%$ da geração $X$ respondeu que só faz em ocasiões especiais, e $3 \%$ da $Y$ "às vezes deixo alguns dias sem fazer", correspondem a $64 \%$ da $Y$, ainda "só faço em ocasiões especiais", $5 \%$ da geração $X$ e 3\% da geração $Y$.

Quanto aos atributos que os homens acreditam que as mulheres acham importantes para eles se tornarem atraentes, para $18 \%$ dos respondentes da geração X o homem deve ser perfumado, assim como para $26 \%$ da geração $Y$. Estar bem vestido corresponde a $16 \%$ da geração $X$ e $21 \%$ geração $Y$, já para $13 \%$ da geração $X$ e $14 \%$ da geração $Y$ o que as mulheres acham mais atraente em um homem é ser bem-sucedido financeiramente.

Apresentam-se as marcas mais lembradas pelos homens (Tabele 7). $\mathrm{Na}$ geração $X$, para $38 \%$ dos homens a marca de shampoo mais lembrada é a Clear, $19 \%$ citaram a Seda e por fim Dove e Natura, ambas com 10\%; outras marcas não tiveram grande representatividade, portanto foram descritas como outras marcas. Com relação à geração $\mathrm{Y}$, para 34\% foi Clear, 24\% Seda e para 10\% a marca que vem à cabeça é a Dove, assim como outras marcas, 10\%; já para $9 \%$ dos homens, a 
marca mais lembrada é a Tressemmé, seguido da Gold, com 4\% e, por fim, a Loreal, correspondente a $3 \%$.

Tabela 7 - Produtos e marcas lembradas para barba, cabelo e perfumaria.

\begin{tabular}{|c|c|c|c|}
\hline \multirow[t]{2}{*}{ Variáveis } & \multirow[t]{2}{*}{ Alternativas } & \multicolumn{2}{|c|}{ Geração Geração Y } \\
\hline & & $\%$ & $\%$ \\
\hline \multirow{4}{*}{$\begin{array}{l}\text { Cuidados com a } \\
\text { barba }\end{array}$} & Está sempre bem-feita & 67,0 & 30,0 \\
\hline & Só faço quando estiver & 29,0 & 3,0 \\
\hline & insuportável & - & 64,0 \\
\hline & $\begin{array}{l}\text { As vezes deixo alguns dias } \\
\text { Só faço em ocasiões importantes }\end{array}$ & 5,0 & 3,0 \\
\hline \multirow{11}{*}{$\begin{array}{l}\text { Em sua opinião qual } \\
\text { o atributo a mulher } \\
\text { acha mais } \\
\text { importante em um } \\
\text { homem }\end{array}$} & Ser perfumado & 18,0 & 26,0 \\
\hline & Estar bem vestido & 16,0 & 21,0 \\
\hline & Ser bem-sucedido & 13,0 & 14,0 \\
\hline & Ter um sorriso bonito & 15,0 & 12,0 \\
\hline & Ter um bom carro & 9,0 & 10,0 \\
\hline & Cabelo bem cuidado & 9,0 & 7,0 \\
\hline & Barba cuidada & 7,0 & 5,0 \\
\hline & Corpo malhado & 4,0 & 4,0 \\
\hline & Não ter barriguinha & 4,0 & 3,0 \\
\hline & Estar sempre na moda & 4,0 & 1,0 \\
\hline & Ter unhas bem-feitas & 2,0 & 1,0 \\
\hline \multirow{9}{*}{$\begin{array}{l}\text { Marca de shampoo } \\
\text { mais lembrada }\end{array}$} & Seda & 19,0 & 24,0 \\
\hline & Dove & 10,0 & 10,0 \\
\hline & Clear & 38,0 & 34,0 \\
\hline & Natura & 10,0 & - \\
\hline & Tresssemé & - & 9,0 \\
\hline & Gold Men & - & 4,0 \\
\hline & Loreal & - & 3,0 \\
\hline & Outros & 24,0 & 10,0 \\
\hline & Branco & - & 6,0 \\
\hline \multirow{9}{*}{$\begin{array}{l}\text { Marca de creme mais } \\
\text { lembrada }\end{array}$} & Natura & 38,0 & 9,0 \\
\hline & Nivea & 33,0 & - \\
\hline & Boticário & 14,0 & 29,0 \\
\hline & Monange & - & 14,0 \\
\hline & Avon & - & 9,0 \\
\hline & Dove & - & 4,0 \\
\hline & Tressemé & - & 4,0 \\
\hline & Outros & - & 10,0 \\
\hline & Em branco & 14,0 & 21,0 \\
\hline \multirow{8}{*}{$\begin{array}{l}\text { Marca de perfume } \\
\text { mais lembrada }\end{array}$} & Natura & 19,0 & 26,0 \\
\hline & Boticário & 62,0 & 30,0 \\
\hline & Ferrari & - & 14,0 \\
\hline & Carolina Herrera Men & - & 6,0 \\
\hline & Hugo Boss & - & 4,0 \\
\hline & Armani & & 4,0 \\
\hline & Outros & 19,0 & 9,0 \\
\hline & Em branco & & 7,0 \\
\hline
\end{tabular}


A Geração X citou qual a marca de perfume que para eles apresentam maior qualidade, sendo que $62 \%$ responderam o Boticário, $19 \%$ a marca Natura e $19 \%$ representado como outras citaram marcas que não obtiveram mais de 1\%. A mesma questão foi realizada para a geração $\mathrm{Y}$, sendo considerada para $30 \%$ dos como a marca o Boticário, seguido da Natura com 26\%, 14\% a Ferrari, ainda 6\% citaram Carolina Herrera Men, por fim 4\% citaram Hugo Boss e Armani.

Seguindo os questionamentos sobre marcas, foi perguntado qual a marca de moda masculina é mais lembrada. Para os homens da geração X, a Nike (24\%), Colcci e Dudalina representam 14\% cada. As marcas Ferracini, Pegada e Lacoste corresponderam a $10 \%$ cada, outros $10 \%$ citaram outras marcas que não obtiveram grande representatividade. Os homens da geração $Y$ citaram como marcas de roupa mais lembradas a da geração Y, a marca Calvin Klein (19\%), Colcci (11\%), Dudalina (10\%). Já as marcas Ellus, Lacoste obtiveram 6\% cada uma, Cavalera $(4 \%)$, Denuncia, Tommy Hilfiger, Nike, Adidas, Jeans, Hugo Boss e Mormai foram citadas por $3 \%$ dos respondentes em cada marca.

Os respondentes também foram instigados a citar um homem famoso considerado vaidoso para eles. Na geração X, 24\% considera o Cristiano Ronaldo. 14\% responderam David Beckham, Rodrigo Lombardi e Roberto Carlos. Tony Ramos e Antonio Banderas foram citados por $10 \%$ dos respondentes, e por fim outros que correspondem a $14 \%$. Para $34 \%$ dos homens da geração $\mathrm{Y}$, o homem vaidoso é Cristiano Ronaldo (34\%), Neymar foi citado por $11 \%$, $9 \%$ consideram o Brad Pit. David Beckham e Caio Castro foram citados por $4 \%$ dos respondentes, Luciano Hulk, Tony Ramos e Cauã Raymond obtiveram 3\% cada um.

Sobre as mulheres vaidosas famosas, $24 \%$ da geração $X$ responderam Gisele Bündchen, 14\% consideram a jornalista Patrícia Poeta, as atrizes Claudia Raia, Giovana Antonelli e Vera Fischer foram citadas por $10 \%$ dos respondentes, a apresentadora Xuxa foi lembrada por $10 \%$. Para a geração $\mathrm{Y}$, as atrizes Angelina Jolie e Bruna Marquezine foram citadas por 14\%, Juliana Paes, Grazi Massafera e Gisele Bündchen foram lembradas por $6 \%$ cada, enquanto Paola Oliveira totalizou $4 \%$, 3\% citaram Isis Valverde, Anita, Xuxa e Camila Pitanga, por fim 23\% citaram outras artistas que não tiveram grande representatividade (Tabela 8). 
Tabela 8 - Marcas famosas e Homens famosos.

\begin{tabular}{|c|c|c|c|}
\hline Variáveis & Alternativas & Geração X & Geração Y \\
\hline & & $\%$ & $\%$ \\
\hline \multirow{17}{*}{$\begin{array}{l}\text { Marca de moda } \\
\text { masculina mais } \\
\text { lembrada }\end{array}$} & Nike & 24,0 & 3,00 \\
\hline & Colcci & 14,0 & 11,0 \\
\hline & Ferracini & 10,0 & - \\
\hline & Dudalina & 14,0 & 10,0 \\
\hline & Pegada & 10,0 & - \\
\hline & Lacoste & 10,0 & 6,0 \\
\hline & Calvin Klein & - & 19,0 \\
\hline & Ellus & - & 6,0 \\
\hline & Cavalera & - & 4,0 \\
\hline & Denuncia & - & 3,0 \\
\hline & Tommy Hilfiger & - & 3,0 \\
\hline & Jeens & - & 3,0 \\
\hline & Adidas & - & 3,0 \\
\hline & Hugo Boss & - & 3,0 \\
\hline & Mormai & - & 3,0 \\
\hline & Outros & 14,0 & 17,0 \\
\hline & Em branco & 5,0 & 4,0 \\
\hline \multirow{13}{*}{$\begin{array}{l}\text { Homens famosos } \\
\text { mais lembrados }\end{array}$} & Cristiano Ronaldo & 24,0 & 34,0 \\
\hline & David Beckham & 14,0 & 4,0 \\
\hline & Rodrigo Lombardi & 14,0 & - \\
\hline & Tony Ramos & 10,0 & 3,0 \\
\hline & Antonio Banderas & 10,0 & - \\
\hline & Roberto Carlos & 14,0 & - \\
\hline & Neymar & - & 11,0 \\
\hline & Brad Pit & - & 9,0 \\
\hline & Luciano Hulk & - & 3,0 \\
\hline & Caio Castro & - & 4,0 \\
\hline & Cauã Raymond & - & 3,0 \\
\hline & Outros & 14,0 & 14,0 \\
\hline & Em branco & - & 11,0 \\
\hline \multirow{18}{*}{$\begin{array}{l}\text { Mulheres } \\
\text { famosas } \\
\text { lembradas }\end{array}$} & Gisele Bündchen & 24,0 & 6,0 \\
\hline & Carolina Ferraz & 10,0 & - \\
\hline & Patricia Poeta & 14,0 & - \\
\hline & Claudia Raia & 10,0 & - \\
\hline & Giovana Antonelli & 10,0 & - \\
\hline & Xuxa & 10,0 & 3,0 \\
\hline & Vera Fischer & 10,0 & - \\
\hline & Bruna Marquezine & - & 14,0 \\
\hline & Angelina Jolie & - & 14,0 \\
\hline & Juliana Paes & - & 6,0 \\
\hline & Grazi Massafera & - & 6,0 \\
\hline & Paola Oliveira & - & 4,0 \\
\hline & Isis Valverde & - & 3,0 \\
\hline & Anita & - & 3,0 \\
\hline & Fernanda Lima & - & 3,0 \\
\hline & Camila Pitanga & - & 3,0 \\
\hline & Outros & 14,0 & 23,0 \\
\hline & Em branco & - & 13,0 \\
\hline \multirow{2}{*}{$\begin{array}{l}\text { Costuma utilizar } \\
\text { acessórios }\end{array}$} & Sim & 38,0 & 40,0 \\
\hline & Não & 62,0 & 60,0 \\
\hline
\end{tabular}


Foi questionado se costumam usar acessórios, 38\% dos homens da geração $X$ responderam sim à questão e $40 \%$ da geração $Y$ (Tabela 9). Ainda sobre acessórios, foi perguntado quais tipos de acessórios eles costumam utilizar: na geração X, 67\% dizem usar relógios. Os acessórios corrente, cinto e aliança tiveram uma frequência de $11 \%$ cada. Os respondentes da geração $\mathrm{Y}, 57 \%$ usam relógio, $9 \%$ óculos, corrente $11 \%$, pulseira $4 \%$, boné $7 \%$, cachecóis $2 \%$, cinto 4 , aliança e anéis $2 \%$.

Tabela 9- Vaidade e acessórios.

\begin{tabular}{|c|c|c|c|}
\hline Variáveis & Alternativas & Geração X & Geração Y \\
\hline & & $\%$ & $\%$ \\
\hline \multirow{10}{*}{$\begin{array}{l}\text { Acessórios } \\
\text { mais } \\
\text { utilizados } \\
\text { citados entre } \\
\text { as gerações }\end{array}$} & Relógio & 67,0 & 57,0 \\
\hline & Óculos & - & 9,00 \\
\hline & Corrente & 11,0 & 11,0 \\
\hline & Pulseira & - & 4,00 \\
\hline & Brinco & - & 2,00 \\
\hline & Boné & - & 7,00 \\
\hline & Cachecóis & - & 2,00 \\
\hline & Cinto & 11,0 & 4,00 \\
\hline & Aliança & 11,0 & 2,00 \\
\hline & Anéis & - & 2,00 \\
\hline \multirow{3}{*}{$\begin{array}{l}\text { Você utiliza } \\
\text { produtos } \\
\text { diferenciados }\end{array}$} & Sim & 10,0 & 33,0 \\
\hline & Não & 90,0 & 67,0 \\
\hline & & & \\
\hline \multirow{6}{*}{$\begin{array}{l}\text { O que é } \\
\text { vaidade para } \\
\text { as gerações }\end{array}$} & Beleza & 10,0 & 13,0 \\
\hline & Autoestima & 24,0 & 27,0 \\
\hline & Cuidado & 24,0 & 27,0 \\
\hline & Bem vestido & 19,0 & 23,0 \\
\hline & Frescura & 19,0 & 6,00 \\
\hline & Outros & 5,00 & 4,00 \\
\hline
\end{tabular}

Fonte: Autores (2017).

Com relação à pergunta "você utiliza produtos diferenciados?", apenas 10\% da geração $X$ dizem usar produtos diferenciados, enquanto na geração $Y$ corresponde a 37\%, já não usam representa 90\% da geração X e 67\% da geração Y. Seguindo, foram questionados quais os produtos os homens mais utilizam: da Geração X somente dois produtos foram citados, 50\% utilizam gel e reparadores de pontas. Já na geração $Y, 16 \%$ respondeu creme hidratante, $28 \%$ gel, $4 \%$ anticéptico bucal, $8 \%$ cera para os cabelos, $36 \%$ creme para pentear e, por fim, espuma para barbear e reparador de pontas, correspondentes a $4 \%$.

As gerações foram questionadas sobre o que é vaidade: correspondente à geração X, 10\% acredita ser beleza, 24\% autoestima, 24\% cuidado, 19\% bem 
vestido, e, por fim, 19\% responderam que vaidade é frescura. Enquanto para a geração Y, 13\% responderam ser beleza, 27\% autoestima, 27\% cuidado, 23\% bem vestido, e para $6 \%$ a vaidade significa vaidade frescura.

Como demonstram os resultados da pesquisa, o comportamento de compra de ambas as gerações possui algumas divergências. A Geração X demonstra ter opiniões mais tradicionais em determinadas questões, a geração $Y$ parece gostar mais do novo, está mais aberta a experiências, ligada às mídias sociais recebe uma influência maior dessas. É importante ressaltar essas divergências, pois as empresas devem estar atentas à maneira que cada um pensa, age, percebe e sente essas mudanças culturais para oferecer produtos de qualidade, e que evidenciam as características de ambos os homens de cada geração, pois eles estão exigentes e em busca da satisfação de suas necessidades.

De modo geral, percebe-se que as grandes empresas de produtos de beleza e cosméticos têm investido na tecnologia de desenvolvimento de novos produtos especificamente masculinos, melhorado a apresentação nos pontos de vendas, na publicidade e propaganda, influenciando cada dia mais no interesse de compra deste público. Porém, mesmo com novos investimentos, ainda existe uma reduzida linha de produtos para homens, se comparado ao público feminino.

É importante ressaltar que atualmente os homens, independentemente de sua geração, estão mais preocupados com a saúde, higiene e beleza. Sua preocupação também é voltada à qualidade dos produtos que consomem.

Porém, deve ser considerado que, devido ao atual momento econômico vivido no país, com aumento de desemprego e consequente redução da renda per capita, os homens podem vir a investir menos em produtos de beleza e cosméticos, pois hoje eles são considerados itens supérfluos. Hoje, pode ser considerado uma ameaça ao mercado de produtos brasileiros a concorrência livre, pois marcas importadas têm assumido importantes fatias de mercado.

Com base nos resultados da pesquisa, sugerem-se algumas ações a empresas do setor de cosméticos masculinos:

- Priorizar a qualidade dos produtos;

- Aumentar o portfólio de produtos;

- Investimentos em marketing voltado especificamente ao público masculino;

- Investir em layout e distribuição dos produtos; 
- Investir em treinamentos focados na mudança do comportamento de consumo dos homens em relação a produtos de beleza;

- Realizar pesquisas de satisfação para constatar novas tendências para satisfazer as necessidades e desejos dos clientes;

Para os vendedores de produtos masculinos, sugere-se:

- Oferecer amostras de novos produtos, colocando nas sacolas de compras dos homens;

- Priorizar o bom atendimento e informações dos produtos;

- Atentar para as exigências específicas deste público;

- Identificar as necessidades dos clientes;

- Enviar ofertas via rede social, e-mail e mensagens;

- Fazer parcerias com lojas de produtos masculinos.

A empresa que definir bem seu planejamento e estratégias de marketing voltadas a explorar a vaidade masculina ganhará vantagens competitivas, pois esse mercado é uma realidade em franco crescimento. Se há demanda precisa existir oferta para suprir essas necessidades, onde há uma troca, o público masculino ganha qualidade e diversificação dos produtos e as empresas atingem seu objetivo final na obtenção de lucro.

\section{CONSIDERAÇÕES FINAIS}

Este estudo buscou identificar como a vaidade pode influenciar no comportamento do consumidor masculino das gerações $\mathrm{X}$ e $\mathrm{Y}$. Como principais resultados, evidencia-se que há tendência dos consumidores masculinos da geração $Y$ comprar e consumir em maior escala que a geração $X$. Assim, na compra de produtos de beleza, $60,0 \%$ dos homens da geração $X$ e $74,7 \%$ da geração $Y$ compram produtos de beleza ao menos uma vez ao mês. No que tange a frequência de compra, observou-se que os homens da geração $X$ efetuam compras em intervalos de tempo mais prolongados em relação aos homens da geração $\mathrm{Y}$, e neste mesmo sentido os homens da geração $Y$ consomem mais produtos de beleza e cuidados com a estética, tais como depilação, manicure, cirurgias plásticas do que os homens da geração $X$. 
Referente às percepções dos consumidores entrevistados quanto à influência da vaidade relacionada ao consumo, identificou-se que os homens buscam melhorar a aparência, para se sentirem bem, com autoestima elevada pelo cuidado com a saúde, higiene pessoal, modo de se vestir.

Analisando os atributos que influenciam o consumo de produtos de beleza e cosméticos utilizados pelo consumidor masculino, a qualidade é o principal item que os consumidores destacaram, seguido por preço, marca e indicação de um profissional da área.

Quanto às percepções que as gerações têm com relação à cirurgia plástica, os entrevistados da geração $X$ não fizeram e não desejam fazer nenhuma mudança no corpo, já na geração $Y$ poucos homens fizeram cirurgias para melhorar a forma física e outros gostariam de promover algumas mudanças na aparência, como cirurgia no nariz, barriga e orelha, demonstrando o processo evolutivo que o homem vem passando ao longo das décadas.

Já com relação aos cuidados com o corpo, a maioria dos respondentes frequenta salão de beleza mensalmente e, entre os cuidados que eles desejam, estão cortes de cabelo, sobrancelha, depilação, cuidados com as unhas, em especial com a barba. No que diz respeito à depilação, a maior parte dos entrevistados diz não realizar, os que fazem costumam depilar peito, abdômen, pernas e o corpo todo. Os homens também destacam o principal motivo que os leva a não se cuidar mais: a falta de tempo, o que se explica pela correria do dia e dia, trabalho, estudos, família que na maioria das vezes exige maior dedicação.

Com a pesquisa, percebe-se que o comportamento das gerações $X$ e $Y$ é divergente, sugerindo que sejam aprofundadas as pesquisas, traçando uma linha de evolução, de comportamento, mudanças culturais e sociais, pois saber como cada geração de consumidores pensa auxilia as empresas a se manterem competitivas. Por fim, este artigo é um estudo relevante para empresas e profissionais das áreas relacionadas à vaidade e beleza masculina, um setor que aumenta seus investimentos em tecnologias e produtos, sendo um dos segmentos que mais cresce no país.

\section{REFERÊNCIAS}


ANDRADE, M. M. Introdução à metodologia do trabalho científico. 10. ed. São Paulo: Atlas, 2010.

BARCELLINI, V. Silicone ou Malhação?. 2014. Disponível em: $<$ http://oficinadamoda.com.br/dica_moda.php?cod_dica_moda=1006>. Acesso em: 01 mai. 2016.

BASTOS, E. R. A influência feminina no consumo masculino de cosméticos. 2005. $157 \mathrm{f}$. Dissertação (Mestrado em Administração). Programa de Pós-graduação e Pesquisa em Administração e Economia. Faculdades IBMEC.

BLACKWELL, R. D., MINIARD, P. W., ENGEL, J. F. Comportamento do consumidor. 9. ed. São Paulo: Pioneira Thomson Learning, 2005.

BLOCH, P. H.; RICHINS, M.L. You look mahvelous: the pursuit of beauty and the marketing concept. Psychology \& Marketing, v. 9, n. 1, p. 3-15, 1992.

BLOCH, P.H.; RICHINS, M.L. Attractiveness, adornments and exchange. Psychology \& Marketing, v. 10, n. 6, p. 467-470, 1993.

COELHO, A. M. R. Guerra de gerações: O que aprender com cada uma delas? 2011. Disponível em: <http://www.administradores.com.br/informe-se/artigos/guerra-degeracoes-o-que-aprender-com-cada-um-delas/51671/>. Acesso em: 01 mai. 2016.

ENGELMANN, D. C. O Futuro da Gestão de Pessoas: como lidaremos com a geração Y? 2007. Disponível em:_<http://www.rh.com.br/Portal/Mudanca/Artigo/4696/o-futuro-dagestao-de-pessoas-como-lidaremos-com-a-geracao-y.html>. Acesso em: 17 jun. 2016.

KOLYESNIKOVA, N., DODD, T. H., WILCOX, J. B. Gender as a moderator of reciprocal consumer behavior. Journal of Consumer Marketing, v. 26, n. 3, p. 200-213, 2009.

KOTLER, P. Administração de Marketing: análise, planejamento, implementação e controle. 5. ed. São Paulo: Atlas, 1998.

KULLOCK, E. Por que as gerações estão no nosso foco?. 2010. Disponível em: $<$ http://www.focoemgeracoes.com.br/index.php/por-que-as-geracoes-estao-no-nossofoco/>. Acesso em: 30 abr. 2016.

LIPKIN, N., PERRYMORE, A. A Geração Y no trabalho. 2. ed. Rio de Janeiro: Campus, 2010.

LOMBARDÍA, P. G.; STEIN, G.; RAMÓN, J. Quem é a Geração Y? HSM Management, v. 70, n. 3, p. 1-7, 2008.

MALDONADO, M. T. A geração $Y$ no trabalho: um desafio para os gestores. 2005. Disponível em: <http://www.rh.com.br/Portal/Mudanca/Artigo/4142/a-geracao-y-notrabalho-um-desafio-para-os-gestores.html>. Acesso em: 09 mai. 2015.

MARCHIORI, F. A influência da vaidade no comportamento do consumidor: um estudo comparativo entre homens e mulheres da geração $Y$. 2014. Trabalho de Conclusão de curso (Graduação em Administração) - Universidade Regional do Noroeste do Estado do Rio Grande do Sul. 
NAVES, F.V.R. A mulher e a decisão de compra de automóvel: propósitos e processos. 2012. 109 f. Dissertação (Mestrado em Profissional em Administração) -Faculdades Integradas de Pedro Leopoldo, Minas Gerais.

NEVES, K. Eles não têm medo da Vaidade. 2012. Disponível em:

<http://www.freedom.inf.br/revista/HC71/cosmeticos.asp>. Acesso em: 01 mai. 2016.

NETEMEYER, R. G.; BURTON, S.; LICHTENSTEIN, D. R. Trait aspects of vanity: measurement and relevance to consumer behavior. Journal of Consumer Research, v. 21, n. 4, p. 612-626, 1995.

OLIVEIRA, S. Geração Y: Era das conexões, tempo de relacionamentos. São Paulo: Clube de Autores, 2009.

ROCHA, A, CHRISTENSEN, C. Marketing: teoria e Prática no Brasil. 2. ed. São Paulo: Atlas, 1999.

SCHIFFMAN, L.G., KANUK, L. L. Comportamento do consumidor. 6. ed. Rio de Janeiro: LTC Livros Técnicos e Científicos Editora S.A, 2000.

SERRANO, D. P. Geração X, Geração Y e Geração Z. 2010. Disponível em: <http://www.portaldomarketing.com.br/Artigos/Geracao_X_Geracao_Y_Geracao_Z.htm >. Acesso em: 25 mai. 2015.

SHETH, J. N., MITTAL, B., NEWMAN, B. J. Comportamento do cliente: indo além do comportamento do consumidor. São Paulo: Altas, 2001.

STAMM, D. Comportamento feminino da geração $Y$ no consumo de produtos de beleza. 2014. Trabalho de Conclusão de curso (Graduação em Administração) -Universidade Regional do Noroeste do Estado do Rio Grande do Sul.

STAUFFER, D. O que motiva cada geração. São Paulo: HSM Managemen, 2003.

THOMPSON, C. J.; HIRSCHMAN, E. C. Understanding the socialized body: a poststructuralist analysis of consumers self-conceptions, body images and self-care practices. Journal of Consumer Research, v. 22, n. 2, p.139-153, 1995.

VELOSO, E.F.R., DUTRA, J.S., NAKATA, L.E. Percepção sobre carreiras inteligentes: diferenças entre as gerações $\mathrm{Y}, \mathrm{X}$ e baby boomers. In: ENCONTRO DA ANPAD, XXXII, 2008, Rio de Janeiro/RJ. Anais..., Local: Anpad, 2008.

WEBSTER, J. M. Image concern and personal cost in the experience of vanity. University of Kentucky, 2001. 